\title{
Method Validation of Total Mercury in Petroleum Green Coke Samples By Cold Vapor Atomic Fluorescence Spectrometry (CVAFS): A Metrological Approach
}

\author{
Adriana Simane Camera*a, Fernando J. S. Oliveirab ${ }^{\mathrm{b}}$, Waldemar de O. P. Filho ${ }^{\mathrm{a}}$, \\ Vera L. A. Frescura ${ }^{a}$ \\ ${ }^{a}$ Departamento de Química, Universidade Federal de Santa Catarina (UFSC), 88040-900 \\ Florianópolis, SC, Brasil. \\ ${ }^{\mathrm{b}}$ Petróleo Brasileiro S.A,Gerência de Meio Ambiente,Coordenação de Resíduos e Áreas Impactadas, \\ Rio de Janeiro, RJ, Brasil.
}

\begin{abstract}
This paper describes the validation of the method for determination of total mercury in petroleum coke samples by cold vapor atomic fluorescence spectrometry after sample treatment for green coke by procedure assisted by microwave. In this context, some validation parameters are evaluated as metrological tools to improve the methodology. The method has been validated in accordance with international protocols and suitable parameters were evaluated as accuracy, precision, linearity, detection e quantification limits, sensitivity, working range and uncertainty of measurement. Limits of detection and quantification have been used to compare different regression models: the Ordinary Least Squares Method and Weighted Least Squares Method. In addition, the evaluation of uncertainty of measurement and error sources allowed the measuring the errors sources contribution and its mapping. The method was applied to ten green coke samples and the results showed that the total mercury concentration in green petroleum coke was between 0.110 and $0.201 \mathrm{mg} \mathrm{kg}^{-1}$, which is very low to be detected for the majority of the analytical techniques. The evaluation of the validation parameters has proved that the proposed method has satisfactory performance.
\end{abstract}

Keywords: Petroleum green coke, mercury, validation, uncertainty of measurement.

\section{INTRODUCTION}

In demand of new alternatives for energy and raw materials, the green petroleum coke (GPC), or just green coke, appears as an interesting option since it can be used as fuel, electricity production, metallurgical industries and also in manufacturing graphite electrodes. GPC is a petroleum byproduct and comes in four basics shapes: green coke (steel grade and anode grade), calcined coke, fluid coke and flexicoke $[1,2,3]$. However, to be used as raw material, it is necessary to evaluate the GPC quality to assure human health in its handling and environment issues through the determination of trace elements such as mercury [1].

Mercury $(\mathrm{Hg})$ naturally occurs in crude oil and gas condensates, in concentration ranges of 0.1 $20.000 \mathrm{ng} \mathrm{g}^{-1}$ and $10-3000 \mathrm{ng} \mathrm{g}^{-1,}$ respectively, depending on geological location. This element causes a direct negative impact on the petroleum industry $[5,6,7,8]$ and it is present in GPC. In addition, Mercury is highly toxic, occupying the third position in a list of 275 most dangerous substances, organized biennially by the Agency for Toxic Substances and Disease Registry (ATSDR) [9].

The applicable methods to GPC for some trace elements are indicated by the American Society for Testing and Materials (ASTM), but do not determine total mercury [1]. Besides the literature reports works developed for the determination of total mercury, inorganic mercury and methylmercury in several matrices and techniques [4, 10 - 24], but in matrices such as GPC is a field to be investigated, requiring a validated method.

About the quality of the analytical results, there are requirements concerned the test results taking to mandatory validation, mainly for new proposed methods. Such requirements follow international directives, based on quality standards for test and calibration laboratories. Among these directives, there are detailed documents bringing steps to validate test methods [25, 26, 27], aim to improve the quality-assurance scheme of laboratories [28], through traceability and uncertainty of measurement of 
analytical results [29]. Therefore numerous regulatory bodies such as Food and Drug Administration (FDA), International Union of Pure and Applied Chemistry (IUPAC), International Conference on Harmonization (ICH), Clinical and Laboratory Standards Institute (CLSI), International Organization for Standardization (ISO) and European Commission (EN), have validation criteria that must be met [30].

Given the need to validate a method for the determination of total mercury in GPC, we propose the validation of the method already developed [31], where an adequate sample preparation, together with the Cold Vapor Atomic Fluorescence Spectrometry (CV AFS) technique proved to be useful, adequate and accessible. The validation parameters were evaluated as accuracy, precision, linearity, limit of detection, limit of quantification, sensitivity, application range and uncertainty of measurement [3235], in order to validate the methodology. The uncertainty of measurement obtained for both certified reference material (BCR 181) and GPC samples it was utilized for a better evaluation of the analytical performance of the proposed method. The method validation has been done to fulfill the validation protocol and evaluate the analytical performance. In addition, the uncertainty of measurement was evaluated with the mapping of error sources.

\section{Materials AND Methods}

\subsection{Instrumentation}

To measure GPC samples and BCR 181 masses, a balance with approximation of $0.0001 \mathrm{~g}$ (AG 204, Mettler Toledo, CH), was used. To prepare GPC samples and BCR 181 microwave oven model Ethos Plus (Milestone, IT) was used to carry out the treatment in Teflon vessels. All studies for determination of total mercury in petroleum GPC samples and BCR 181 were carried out in an atomic fluorescence spectrometer Mercur Duo Plus from Analytik Jena (Jena, DE). The instrument is equipped with an mercury low pressure lamp (UVU5) using the main mercury line at $253.7 \mathrm{~nm}$, which is applied for excitation of mercury atoms. The photomultiplier voltage was set up at $353 \mathrm{~V}$. Two enrichment stages through gold and platinum collectors (AuPt10) are possible to be used. A PEEK reactor in an incidence angle of $90^{\circ}$ between sample/acid and reducing agent was utilized to accomplish the mixture of the sample and reactants, achieving the mercury vapor formation. It is extracted in a gas/liquid separator and dissolved in a membrane using argon (White Martins, SP, BR, $99.997 \%$ purity) in counter flow $\left(10 \mathrm{~mL} \cdot \mathrm{min}^{-1}\right)$. This method is described in an earlier study [31].

\subsection{Reagents, Standards and Samples}

The chemicals used in the studies and determinations were analytical grade. High purity water with a resistivity of $18.2 \mathrm{M} \Omega \mathrm{cm}$ was deionized in a Milli-Q system (Millipore, Beadford, MA, US), and applied for the preparation of all samples and solutions. Both, nitric acid $\left(\mathrm{HNO}_{3}\right) 65 \% \mathrm{~m} / \mathrm{m}(\mathrm{Carlo}$ Erba Reagenti, Milan, IT) and hydrochloric acid ( $\mathrm{HCl}), 37 \%$ (Vetec, Rio de Janeiro, BR), were purified by double sub-boiling distillation in a quartz system (Kürner Analysentechnik, Rosenheim, DE). Hydrofluoric acid (HF) 50\% (Química Moderna Industry and e Commerce LDTA, São Paulo, BR) was submitted to a triple sub-boiling distillation in a polytetrafluoroethylene system (Kürner Analysentechnik, Rosenheim, DE), prior to its use in the sample digestion and calibration solutions preparation.

Mercury monoelemental standard solution (II) (SpecSol, Quimlab Química \& Metrologia, São Paulo, $\mathrm{BR}$ ), has been used to prepare the calibration curves, in a range from 25 up to $400 \mathrm{ng} \mathrm{L}^{-1}$, with calibration solutions at 25, 50,100, 200 and $400 \mathrm{ng} \mathrm{L}^{-1}$. Two stock solutions denominated SS1 and SS2 (SS1, $10 \mathrm{~m} \mathrm{~L}^{-1}$, afterwards SS2 - from SS1 - $10 \mu \mathrm{g} \mathrm{L}^{-1}$ ), were prepared to build this calibration set. For mercury vapor generation, the reducer was tin (II) chloride, $\mathrm{SnCl}_{2} \cdot \mathrm{H}_{2} \mathrm{O} 3.0 \% \mathrm{~m} / \mathrm{v}(98 \%$, Sigma Aldrich, US). To guarantee the stability of $\mathrm{Hg}^{2+}, 150 \mu \mathrm{L}$ of the potassium permanganate, $\mathrm{KMNO}_{4} 0.04 \% \mathrm{~m} / \mathrm{v}$ (Merck S. A. Rio de Janeiro, BR), was added prior to the mercury vapor generation. To eliminate the excess of $\mathrm{KMnO}_{4}, 75 \mu \mathrm{L}$ of the hydroxylamine hydrochloride, $\mathrm{HONH}_{3} \mathrm{Cl}$ (E. Merck, Darmstadt, DE), was added stoichiometrically. The reducing agent $\mathrm{SnCl}_{2}$ was prepared by dissolving this salt $(3 \% \mathrm{~m} / \mathrm{v})$ in $\mathrm{HCl}(4 \% \mathrm{v} / \mathrm{v})$ medium. Also, $\mathrm{HCl}$ is used to acidify the sample solution prior the reaction with the reducer with concentration of the $4.0 \% \mathrm{v} / \mathrm{v}$.

BCR 181 (concentration of total mercury is $0.138 \pm 0.011 \mu \mathrm{g} \mathrm{g}^{-1}$, Community Bureau of Reference, Brussels, BE), has been used in the development of this work. Ten petroleum GPC samples from refining industry were analyzed to test the proposed conditions. 
Method Validation of Total Mercury in Petroleum Green Coke Samples By Cold Vapor Atomic Fluorescence Spectrometry (CVAFS): A Metrological Approach

\subsection{Samples Preparation and Analytical Procedures}

The green petroleum coke was retted in an agatha mortar, then crushed in a ball mill (MM200, Retsch, US), and sieved to obtain a fine powder with particle size smaller than $85 \mu \mathrm{m}$. Approximately $100 \mathrm{mg}$ of sample was used for the mercury determinations.

Digestion procedure assisted by microwave was carried out using the mass of BCR $181(0.100 \mathrm{~g})$, directly weighed into the microwave vessels. The reactants $\left(4 \mathrm{~mL} \mathrm{HNO}_{3}, 1 \mathrm{~mL} \mathrm{HCl}\right.$ and $\left.0.5 \mathrm{~mL} \mathrm{HF}\right)$ were added and submitted to the microwave program [31]. After digestion program the mixtures were quatitatively transferred to polyethylene tubes and brought to a final volume of $50.0 \mathrm{~mL}$ with purified water. At the end of the pocedure, solid particles remained in all solutions, and the same dilution procedure applied to the supernatant of the extracts was used for the digested sample solutions before the measurements by CV AFS.

To promote the mercury vapor generation the sample, $\mathrm{HCl}$ and the reducing agent were continuously inserted in instrument by a peristaltic pump through three different tube lines and mixed inside the PEEK reactor. The resultant mixture was transported to a gas-liquid separator where the generated vapor of mercury was extracted from the solution and carried by a argon flow to a Au-Pt trap. After the thermal realese the fluorescence signal was measured. The whole procedure is described in a previous work [31].

\subsection{Validation Procedures and Uncertainty of Measurement}

Table 1 shows the validation protocol for mercury determination. The chosen parameters and metodologies have been evaluated in accordance with suitable protocols, as well as the acceptance criteria [36-37]. The uncertainty of measurement was studied following international guides [38-40]. We can highlight the use of uncertainty data, which allows the use of the Normalized Error Test (NET) - a tool to evaluate the accuracy [32]:

$N E=\frac{x-\bar{x}}{\left(U_{C}^{2}+U_{m}^{2}\right)^{1 / 2}}$

Where:

$N E$ is the Normalized Error;

$x$ is the measured $\mathrm{Hg}$ content in the sample;

$\bar{x}$ is the reference value ( $\mathrm{n}$ this work, the BCR $181 \mathrm{Hg}$ content);

$U_{C}^{2}$ is the uncertainty of reference material (in this work, BCR 181 uncertainty);

$U_{m}^{2}$ is the uncertainty of measurement (expanded uncertainty).

Table1. Validation protocol and validation results for total mercury determination in petroleum GPC samples by CV AFS.

\begin{tabular}{|c|c|c|c|c|}
\hline Parameter & Methodology ${ }^{36,37}$ & Acceptance criteria & Results & $\begin{array}{l}\text { Fulfill the } \\
\text { acceptance } \\
\text { criteria? }\end{array}$ \\
\hline Accuracy & $\begin{array}{c}\text { Normalized error; } \\
\text { Recovery }\end{array}$ & $\begin{array}{c}\leq 1.0 \\
\geq 90-\leq 120 \%\end{array}$ & $\begin{array}{c}0.071 \\
95-109 \%\end{array}$ & $\begin{array}{l}\text { Yes } \\
\text { Yes }\end{array}$ \\
\hline Precision & RSD for triplicates & $\mathrm{RSD} \leq 5.0 \%$ & 3.16 & Yes \\
\hline Linearity & $\begin{array}{l}\text { Correlation Coefficient } \\
(\text { OLSM and WLSM)* }\end{array}$ & $r \geq 0.999$ & $\begin{array}{c}0.9998 \\
\text { (OLSM and } \\
\text { WLSM) }\end{array}$ & Yes \\
\hline $\operatorname{LOD}\left(\mu \mathrm{g} \mathrm{L}^{-1}\right)$ & $\begin{array}{c}\text { Crossing between } \\
\text { prevision/analytical curves } \\
\text { and } 3 * \text { SD/curve slope }\end{array}$ & $\begin{array}{c}\text { LOD } \leq 70 \% \text { of the first } \\
\text { concentration level of the } \\
\text { analytical curve, not } \\
\text { considering white }\end{array}$ & $\begin{array}{c}0.005 \text { (OLSM); } \\
0.002 \text { (WLSM); } \\
0.003 \text { (Anvisa) }\end{array}$ & Yes \\
\hline $\operatorname{LOQ}\left(\mu \mathrm{g} \mathrm{L}^{-1}\right)$ & $\begin{array}{c}\text { Crossing between } \\
\text { prevision/analytical curves } \\
\text { and } 10 * \text { SD/curve slope } \\
\end{array}$ & $\begin{array}{l}\text { LOQ } \leq \text { first concentration } \\
\text { level in analytical curve, not } \\
\text { considering white }\end{array}$ & $\begin{array}{c}0.01 \text { (OLSM); } \\
0.003 \text { (WLSM); } \\
0.01 \text { (Anvisa) }\end{array}$ & Yes \\
\hline Sensitivity & $\begin{array}{l}\text { Analytical curves slopes } \\
\text { comparison }\end{array}$ & $\begin{array}{l}\text { Comparison between } \\
\text { analytical curves slopes }\end{array}$ & $\begin{array}{c}0.0009 \text { (Hg addition } \\
\text { in BCR 181) } \\
0.0010 \text { (Hg addition } \\
\text { in green coke) } \\
0.0010 \text { (aqueous } \\
\text { standards) }\end{array}$ & Yes \\
\hline
\end{tabular}


Adriana Simane Camera et al.

\begin{tabular}{|c|c|c|c|c|}
\hline $\begin{array}{c}\text { Application range } \\
\left(\mu g \mathrm{~L}^{-1}\right)\end{array}$ & $\begin{array}{l}\text { Range between LOQ and } \\
\text { last concentration level in } \\
\text { analytical curve }\end{array}$ & - & $0.0106-0.400$ & Yes \\
\hline $\begin{array}{l}\text { Uncertainty of } \\
\text { Measurement }\end{array}$ & $\begin{array}{l}\text { Described procedures in } \\
\text { ISO/GUM and } \\
\text { Eurachem/CITAC } \\
38-40\end{array}$ & & $\begin{array}{l} \pm 0.048(\text { OLSM }) \\
\pm 0.036(\text { WLSM })\end{array}$ & Yes \\
\hline
\end{tabular}

* OLSM: Ordinary Least Squares Method

* WLSM: Weighted Least Squares Method

\section{RESUlTS AND DiscuSSION}

\subsection{Method Validation}

The usual steps for of a new test method include development and publication (optional) and the validation of this method. Table 1 shows the validation results in summary form, and which will be presented below.

\section{Accuracy}

NE provides a parameter value to verify method accuracy. The uncertainties of BCR $181\left(0.138 \mu \mathrm{g} \mathrm{g}^{-}\right)$ and the method $\left(0.155 \mu \mathrm{g} \mathrm{g}^{-1}\right)$ were used according equation 1 . The obtained value was less than or equal the $1(\leq 1)$. In this case, as recommended by the INMETRO (Institute National of Metrology, Quality and Technology, BR) [32], the results are satisfactory (NE is 0.0071). The low normalized error has indicated excellent agreement between obtained and certified value. The recovery test also fulfilled the acceptance criteria (95\% to $105 \%$ ).

\section{Precision}

The precision, which has been evaluated by RSD (3.16) in a true triplicate test, was satisfactory considering the low concentration of the total mercury in the GPC samples, and fulfilled the acceptance criteria. The precision levels are closed to other published Hg determinations [12].

\section{Linearity}

All correlation coefficients complied with acceptance criteria (at least 0.999). In addition, two possible regression models were evaluated: The Ordinary Least Squares Method (OLSM) and Weighted Least Squares Method (WLSM).

The use of OLSM for a linear regression directly from instrumental response data (in this method the corresponding integrated absorbance) versus the known input value (in this method total $\mathrm{Hg}$ concentration, in $\mu \mathrm{g} \mathrm{L}^{-1}$ ) is an approximation and can result in systematic errors [42]. OLSM is a regression model suitable only when the data sets are verified through outliers test, residues normality test, independence of residues and homoscedasticity test [43].

The use of WLSM takes into account the standard deviation of each level individually. In this case, the lowest standard deviation has greater contribution to obtain the angular and linear coefficients of the linear regression equation. As the linearity obtained by OLSM was identical to linearity obtained by WLSM (0.9998), the complementary tests for OLSM mentioned above were not necessary to be performed.

\section{Limit of Detection (LOD) and Limit of Quantification ( $L O Q)$}

The method of crossing the forecast and analytical curves was used here [41]. The prevision limit curves (PLC) and confidence limit curves (CLC) are plotted for graphical verification of the instrumental response dispersion for each analytical curve pattern. These curves contribute, visually, to a greater or lesser reliability of the linear regression along the working range. The PLC are represented by the superior prevision limit (SPL) and inferior prevision limit (IPL) curves. The closer to the analytical curve graphically, the greater the precision of the data obtained experimentally [41]. To obtain SPL and IPL, an OLSM regression between the known input variables on the x-axis (in the case, concentration of the $\mathrm{Hg}$ in $\mu \mathrm{g} \mathrm{L}^{-1}$ ), and y-axis were used values calculated according the Equations 2 to 6 .

$Y_{P I}=y_{i c a l c}-t_{95 \% ; n-2} \times \sqrt{s_{r e s}^{2} /\left(p+x_{i}^{2} \times s_{a}^{2}+2 x_{i} \times \operatorname{cov}(a, b)+s_{b}^{2}\right)}$ 
Where:

$Y_{P I}$ is value of the point in the y-axis in IPL curve

$y_{i c a l c}$ is the instrumental response estimated by the regression equation of the original data by OLSM.

$t_{95 \% ; n-2}$ is the student $\mathrm{t}$ for $95 \%$ confidence and $\mathrm{n}-2$ degrees of freedom.

$x_{i}$ is the $\mathrm{x}$-axis individual value.

$n$ is the number of levels of the analytical curve (in this case, 6).

$S_{\text {res }}$ is given by equation 3 .

$S_{a}$ is given by equation 4 .

$S_{b}$ is given by equation 5 .

$\operatorname{cov}(a, b)$ is the covariance between the angular coefficient $a$ and linear $b$ of the linear regression.

$S_{\text {res }}=\frac{\sqrt{m \times b^{2}+\sum y_{i}^{2}+a^{2} \times \sum x_{i}^{2}+2 a b \times \sum x_{i}-2 b \times \sum y_{i}-2 a \times \sum x_{i} y_{i}}}{m-2}$

Where:

$m$ is the number of calibration standard reading (in this case, 18).

$y_{i}$ is the value of the individual instrumental response.

$\mathrm{S}_{a=} S_{\text {res }} \times \sqrt{m / S_{x x}}$

$\mathrm{S}_{b=} S_{\text {res }} \times \sqrt{\sum \frac{x_{i}^{2}}{S_{x x}}}$

Where $S_{x x}$ is given by equation 6 .

$\mathrm{S}_{x x=m}{ }_{x}$
$\sum x_{i}^{2}-\left(\sum x_{i}\right)^{2}$

For purposes of comparison, regression was performed by WLSM too. In this regression type, the individual variances of each level of concentration along the analytical curve were used. The SPL and IPL curves limits were uses for the calculation of the LOD and LOQ (see details in appendix A).

OLSM has been selected for LOD. In the case, there was a greater margin of safety for the developed method, since GPC samples with low concentration may have signals low enough to be confused with variations of background. For LOQ it was also adopted to have the same treatment. Therefore, in this case, the commonly used OLSM has fulfilled Linearity and LOD/LOQ validation parameters.

\section{Sensitivity}

Sensitivity has evaluated by the comparison between analytical curves slopes for mercury addition in BCR 181, GPC samples and aqueous standards. No significant differences have been observed, allowing the aqueous standards use without any sensitivity trouble. Selectivity has not been evaluated, because the instrument detector is selective for mercury and in addition, during the development stage of the method, all ideal conditions were found [31]. Therefore, in the absence of variables to change, the robustness has not been evaluated. The uncertainty of measurement has enabled the NE use in accuracy evaluation, the error sources mapping, besides being a validation parameter.

\section{Application Range}

Faced the calibration curve data, $\mathrm{Hg}$ contents of the samples and LOD / LOQ issues, the working/application range has been defined between 0.0106 to $0.400 \mu \mathrm{g} \mathrm{L}^{-1}$. This range easily covers the test method scope [31]. 


\subsection{Uncertainty of Measurement}

Table 2 shows the final uncertainty calculation for the proposed method. The error sources mapping was started in measurement equation below:

$C=w \times \frac{V_{F 2}}{V_{\text {pip }}} \times \frac{V_{F 1}}{m_{\text {am }}}$

Where:

$C$ is the Mercury concentration, in $\mathrm{ng} \mathrm{g}^{-1}$;

$w$ is the Mercury concentration, in $\mathrm{ng} \mathrm{L}^{-1}$;

$V_{F 2}$ is the volume of the reading sample;

$V_{p i p}$ is the volume of the aliquot of the supernatant;

$V_{F l}$ is the volume of the digested sample;

$m_{a m}$ is the sample mass.

Table2. Final Uncertainty calculation. ( $k=$ coverage factor)

(*) See details about sensitivity coefficient calculation in appendix B.

\begin{tabular}{|c|c|c|c|c|}
\hline Uncertainty Source & Value & $\begin{array}{c}\text { Probability } \\
\text { Distribution }\end{array}$ & $\begin{array}{c}\text { Sensitivity } \\
\text { coefficient }\end{array}$ & $\begin{array}{c}\text { Contribution } \\
(\%)\end{array}$ \\
\hline$w$ & $1.69 \mathrm{ng} \mathrm{L}^{-1}$ & Normal & $10 \mathrm{~L} \mathrm{~g}^{-1}$ & 50.07 \\
\hline$m_{\text {am }}$ & $0.00006 \mathrm{~g}$ & Normal & $1381.9 \mathrm{ng} \mathrm{g}^{-2}$ & 0.00 \\
\hline $\begin{array}{c}\text { Combined calibration } \\
\text { solutions }\end{array}$ & $3.11 \mathrm{ng} \mathrm{L}^{-1}$ & Normal & $10 \mathrm{~L} \mathrm{~g}^{-1}$ & 42.23 \\
\hline$V_{p i p}$ & $0.0065 \mathrm{~mL}$ & Normal & $184.25 \mathrm{ng} \mathrm{g}^{-1} \mathrm{~mL}^{-1}$ & 0.05 \\
\hline$V_{F 2}$ & $0.2351 \mathrm{~mL}$ & Normal & $9.21 \mathrm{ng} \mathrm{g}^{-1} \mathrm{~mL}^{-1}$ & 0.15 \\
\hline$V_{F 1}$ & $0.0005 \mathrm{~L}$ & Normal & $2763.7 \mathrm{ng} \mathrm{g}^{-1} \mathrm{~L}^{-1}$ & 0.06 \\
\hline Measurement repeatability & $6.52 \mathrm{ng} \mathrm{g}$ & Normal & 1.00 & 7.40 \\
\hline Combined uncertainty & $\begin{array}{c}\text { Effective } \\
\text { degrees of } \\
\text { freedom }\end{array}$ & $\mathbf{k}$ & $\begin{array}{c}\text { Expanded Uncertainty (confidence } \\
\text { level = 95\%) }\end{array}$ \\
\hline $23.9 \mathrm{ng} \mathrm{g}^{-1}$ & 362 & 2.01 & \multicolumn{2}{|c|}{$48.17 \mathrm{ng} \mathrm{g}^{-1}$} \\
\hline
\end{tabular}

Based on measurement equation, the error sources mapping is illustrated in Figure 1, the Ishikawa Diagram. The main axis in the diagram has all measurement equation variables, besides the measurement repeatability and combined calibration solutions errors. The sum of the standard deviations for each error source was done in agreement with ISO GUM guide [39]. According to the Table 2 data, the uncertainty of linear regression matches to about $50 \%$ of the total uncertainty of measurement. This error source is generated for the mathematical model for the calibration data on intensity axis. It does not depend on the linearity, but it depends on the precision on each concentration level. So, this is a random error, which is related to instrumental limitations. The combined calibration solutions error matches to about $42 \%$ of the total uncertainty of measurement. As the preparation of these solutions was volumetric, the most effective factor to generate this error source was the repeatability of the used pipettes, which have presented standard deviations of 1.06 (100 $\mu \mathrm{L}$ pipette) and $2.71 \mu \mathrm{L}(1000 \mu \mathrm{L}$ pipette). Once again, a random error related to instrumental limitations. The expanded uncertainty has been used as the true confidence limit for each measurement of the proposed method, as shown in Table 3.

\subsection{Application to Green Petroleum Coke Samples}

Ten GPC samples were submitted to the microwave assisted digestion procedure and the concentration of total mercury was measured by CV AFS [31]. The results presented in Table 3 show that the concentration of total mercury in these samples of petroleum GPC is very low and the use of a technique with high sensitivity as CV AFS is suitable. The results also suggest that petroleum GPC can be used as an alternative source of energy, without any significant harm to the environment in which the presence of total mercury can cause concern. 


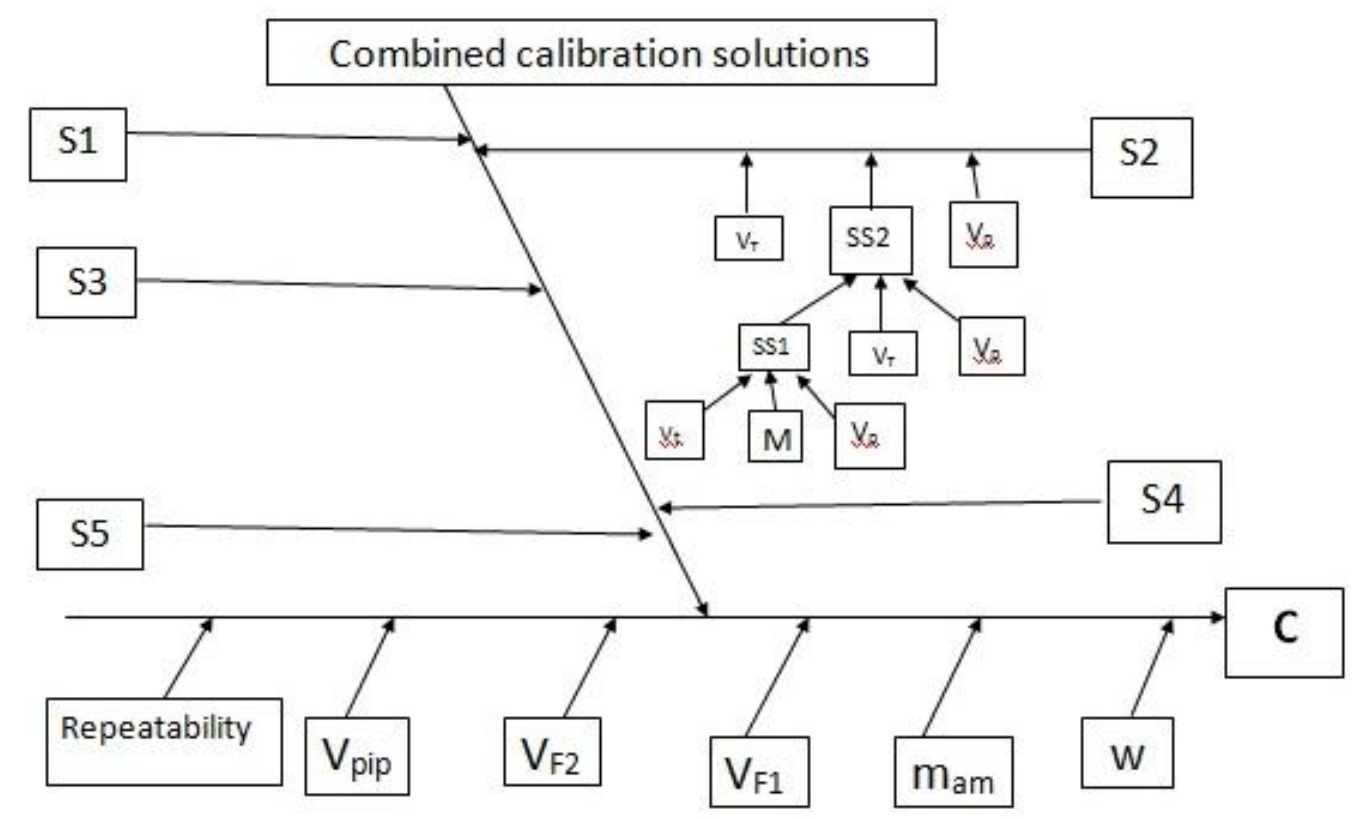

Fig1. Ishikawa Diagram for error sources mapping. $C, w, m_{a m}, V_{F 1}, V_{F 2}, V_{p i p}$ : see measurement equation. M: uncertainty of monoelemental standard solution; S1 to S5: uncertainty of calibration solutions 1 to 5, respectively; $V_{p}$ : uncertainty of measured volume by a pipette; $V_{T}$ : uncertainty of the final volume solutions $(50$ $m L) ; V_{t}$ : uncertainty of final volume solutions $(15 \mathrm{~mL}) ; S S 1$ : uncertainty of the stock solution 1 concentration; SS2: uncertainty of the stock solution 2 concentration.

Table3. Concentration values ( $n=3$ ) for total mercury in petroleum GPC samples, with confidence level of $95 \%$ by $C V A F S$.

\begin{tabular}{|c|c|}
\hline Samples & Concentration total $\mathrm{Hg}\left(\mathrm{mg} \mathrm{kg}^{-1}\right)$ \\
\hline BCR 181 & $0.134 \pm 0.05$ \\
Green coke 1 & $0.116 \pm 0.05$ \\
\hline Green coke 2 & $0.201 \pm 0.05$ \\
\hline Green coke 3 & $0.110 \pm 0.05$ \\
\hline Green coke 4 & $0.120 \pm 0.05$ \\
\hline Green coke 5 & $0.150 \pm 0.05$ \\
\hline Green coke 6 & $<\mathrm{LOD}$ \\
\hline Green coke 7 & $<\mathrm{LOD}$ \\
\hline Green coke 8 & $<\mathrm{LOD}$ \\
\hline Green coke 9 & $<\mathrm{LOD}$ \\
\hline Green coke 10 & $<\mathrm{LOD}$ \\
\hline
\end{tabular}

\section{Conclusions}

In this work, it was proposed to validate the method for the determination of the total concentration of mercury in samples of green petroleum coke. The method validation allowed a better assessment of the analytical performance, besides meeting international protocols for a method establishment. It can be considered a previous stage of a normalized method in the future. The uncertainty of measurement calculation has contributed to a better accuracy evaluation, a secure confidence limit determination, and error sources mapping. The uncertainty of measurement has shown a low systematic error influence too. These facts may have a superior evaluation in the future for example through a proficiency program.

\section{ACKNOWLEDGMENTS}

The authors are thankful to Conselho Nacional de Desenvolvimento Científico e Tecnológico $(\mathrm{CNPq}$, Brasília, Brazil), INCT - Energia e Ambiente (Salvador, Brazil) and to Petróleo Brasileiro S. A. (Petrobras, Rio de Janeiro, Brazil) for financial support. 


\section{REFERENCES}

[1] G. James. Handbook of petroleum product analysis. ISBN: 0-471-20346-7. ed. [S.1.]: John Wiley \& Sons, 2002.

[2] EPA. Petroleum coke category analysis and hazard characterizantion. [S.1.]. 2008.

[3] PETROBRÁS. Coque verde de petróleo. Disponivel em: <http://www.br.com.br/wps/portal/ portalconteudo/produtos/paraindustriasetermeletricas/coqueverededepetroleo/!ut/p/c4/04_SB8K8xLL M9MSSzPy8xBz9CP0os3hLf0N_P293QwN3AyM3AyMfNy8LfxdHAwMDc_2CbEdFAN9fqmc !/>. Acess: 15 March 2015.

[4] F. V. M. Pontes; M. C. Carneiro; D. S. Vaitsman; M. I. Monteiro; A. A. Neto; M. L. B. Tistão. Investigation of the Grignard reaction and experimental conditions for the determination of inorganic mercury and methylmercury in crude oils by GC-ICP-MS, Fuel, 116 (2014) 421-426. doi:10.1016/j.fuel.2013.08.025.

[5] N.S. Bloom. Analysis and stability of mercury speciation in petroleum hydrocarbons, Fresenius Journal Analytical Chemistry, 366 (2000) 438-443.

[6] S. M. Wilhelm, N. S. Bloom, Mercury in petroleum. Fuel process Technol., 63 (2000) 1-27.

[7] L. Liang; M. Horvat; V. Fajon; N. Prosenc; H. Li; P. Pang. Comparison of improved combustion/trap technique to wet extraction methods for determination of mercury in crude oil and related products by atomic fluorescence, Energy Fuel, 17 (2003) 1175-1179. doi: 10.1021/ef030042j.

[8] R. A. A. Munoz; P. R. M. Correia; A. N. Nascimento; C. S. Silva; P. V. Oliveira; L. Angnes. Electroanalysis of crude oil and petroleum-based fuel for trace metals. Energy Fuel, 21 (2007) 295-302. doi: 10.1021/ef0603941.

[9] ATSDR. Summary data for 2015 priority list of hazardous substances, Department of Health and Human Services. Public Health Service. Atlanta: [s.n.], (1999), 1.

[10] D. P. Torres; M. B. Martins-Teixeira; S. Cadore; H. M. Queiroz. Method validation for control determination of mercury in fresh fish and shrimp samples by solid sampling thermal decomposition/amalgamation atomic absorption spectrometry. Journal of Environmental Science and Health, Part B, 50, n. 7 (2015), 514-522. doi: 10.1080/03601234.2015.1018764.

[11] S. N. Guilhen; M. A. F. Pires; E. S. K. Dantas; F. V. Xavier. Validation of an analytical method for the determination of total mercury in urine samples using cold vapor atomic absorption spectrometry (CV-AAS). Case study. Química Nova, São Paulo (2010). V. 33, No. 6, 1285-1290. doi: 10.1590/S0100-40422010000600013.

[12] Li-Jun Shao; Wu-Er Gan; Qing-De Su. Determination of total and inorganic Mercury in fish samples with on-line oxidation coupled to atomic fluorescence spectrometry. Analytica Chimica Acta. 562 (2006) 128-133. doi:10.1016/j.aca.2006.01.039.

[13] A. F. Lima; M. C. Da Costa; D. C. Ferreira; E. M. Richter; R. A. A. Munoz. Fast ultrasoundassisted treatment of inorganic fertilizers for mercury determination by atomic absorption spectrometry and microwave-induced plasma spectrometry with the aid of the cold-vapor technique, Microchemical Journal, 118 (2015) 40-44. doi:10.1016/j.microc.2014.07.012.

[14] A. S. Ribeiro; M. A. Vieira; A. J. Curtius. Slurry sampling for mercury determination in sediments, sewage sludge and coal samples by cold vapor atomic absorption spectrometry, Journal of the Brazilian Chemical Society, 15 (2004). doi.org/10.1590/S010350532004000600007.

[15] E. J. dos Santos; A. B. Herrmann; M. A. Vieira; V. L. A. Frescura; A. J. Curtius. Evaluation of slurry preparation procedures for the determination of mercury by axial view inductively coupled plasma optical emission spectrometry using on-line cold vapor generation. Spectrochimica Acta, Part B: Atomic Spectroscopy, 60 (2005) 659-665. doi:10.1016/j.sab.2004.12.009.

[16] M. A. Vieira; A. S. Ribeiro; L. F. Dias; A. J. Curtius. Determination of mercury and selenium in biological materials by chemical vapor generation electrothermal vaporization inductively coupled plasma mass spectrometry using isotope dilution calibration after microwave-assisted digestion with Aqua Regia. Journal of the Brazilian Chemical Society, 17 (2006). doi.org/10.1590/S0103-50532006000500016. 
[17] I. M. Dittert; T. de A. Maranhão; D. L. G. Borges; M. A. Vieira; B. Welz; A. J. Curtius. Determination of mercury in biological samples by cold vapor atomic absorption spectrometry following cloud point extraction with salt-induced phase separation. Talanta, 72 (2007) 17861790. doi: 10.1016/j.talanta.2007.02.012.

[18] A. de Jesus; A. V. Zmozinkki; M. A. Vieira; A. S. Ribeiro; M. M. da Silva. Determination of mercury in naphtha and petroleum condensate by photochemical vapor generation atomic absorption spectrometry. Microchemical Journal, 110 (2013) 227-232. doi:10.1016/j.microc. 2013.03.019

[19] D. P. Torres; D. L. G. Borges; V. L. A. Frescura; A. J. Curtius, A simple and fast approach for the determination of inorganic and total mercury in aqueous slurries of biological samples using cold vapor atomic absorption spectrometry and in situ oxidation. Journal Analytical Atomic Spectrometry, 24 (2009) 1118-1122. doi: 10.1039/B816622F

[20] D. P. Torres; M. A. Vieira; A. S. Ribeiro; A. J. Curtius, Determination of inorganic and total mercury in biological samples treated with tetramethylammonium hydroxide by cold vapor atomic absorption spectrometry using different temperatures in the quartz cell. Journal Analytical Atomic Spectrometry, 20 (2005) 289-294. doi: 10.1039/B416167J

[21] D. P. Torres; M. B. Martins-Teixeira; E. F. Silva; H. M. Queiroz. Method development for the control determination of mercury in seafood by solid-sampling thermal decomposition amalgamation atomic absorption spectrometry. Food Additives \& Contaminants: Part A, 29 (2012) 625-632. doi: 10.1080/19440049.2011.642310.

[22] J. L. Rodrigues; B. L. Batista; S. S. Souza; V. C. O. Souza; J. F. Barbosa; D. P. Torres; A. J. Curtius; J. A. G. Neto. Determination of total and inorganic mercury in whole blood by cold vapor inductively coupled plasma mass spectrometry with alkaline sample preparation. Colloquium Spectroscopicum Internationale, 24 (2009) 1414-1420. Access: 09 april 2015, http://producao.usp.br/handle/BDPI/20225

[23] W. Geng; T. Nakajima; H. Takanashi; A. Ohki. Determination of mercury in ash and soil samples by oxygen flask combustion method-cold vapor atomic fluorescence spectrometry (CV AFS). Journal of Hazardous Material, 154 (2008) 325-330. doi: 10.1016/j.jhazmat.2007.10.029.

[24] T. de A. Maranhão; J. S. A. Silva; R. M. Andrade; V. L. A. F. Bascuñan; F. J. S. Oliveira; A. J. Curtius. Determination of arsenic and mercury in acetic acid extract by vapor generation coupled to atomic spectrometry for solid waste classification. Microchemical Journal, 106 (2012) 139146. doi: 10.1016/j.microc.2012.06.001.

[25] INMETRO. Laboratory Accreditation (ABNT NBR ISO/IEC 17025:2005). Available: <http://www.inmetro.gov.br/credenciamento/acre_lab.asp>.

[26] GUIDELINE, I. H. T. Validation of Analytical Procedures: Text and Methodology Q2 (R1). [S.1.]: [s.n.], (2005). p. 18. Available: <http://www.ich.org/fileadmin/Public_Web_Site/ ICH_Products/Guidelines/Quality/Q2_R1/Step4/Q2_R1_Guideline.pdf>.

[27] F. Leite. Validação em análise química. 5a . ed. Campinas: Editora Átomo (2008). 357 p.

[28] E. Rozet; R. D. Marini; E. Ziemons; W. Dewe; S. Rudaz; B. Ph H. Boulanger. Total error and uncertainty: Friends or foes? Trends in Analytical Chemistry (2011), V. 30, No. 5. doi:10.1016/j.trac.2010.12.009

[29] I. Taverniers; E. V. Bockstaele; M. D. Loose. Trends in quality in the analytical laboratory. I. Traceability and measurement uncertainty of analytical results. Trends in Analytical Chemistry (2004), V. 23, No. 7. doi:10.1016/S0165-9936(04)00733-2.

[30] E. Rozeta; S. Rudazb; R. D. Marinia; E. Ziémonsa; B. Boulangerc; Ph Huberta. Models to estimate overall analytical measurements uncertainty: Assumptions, comparisons and applications. Analytica Chimica Acta, 702 (2011) 160- 171. doi:10.1016/j.aca.2011.06.055

[31] A. S. Camera; T. A. Maranhão; F. J. S. Oliveira; J. S. A. Silva; V. L. A. Frescura. Total mercury determination in petroleum green coke and oily sludge samples by Cold Vapor Atomic Fluorescence Spectrometry. Journal of the Brazilian Chemical Society (2015), 10, 2116. http://dx.doi.org/10.5935/0103-5053.20150197.

[32] INMETRO. Orientações sobre validação de métodos de ensaios químicos. DOQ-CGCRE-008. In: INMETRO Protocolo do Instituto Nacional de Metrologia, Normalização e Qualidade Industrial. Xerém, RJ: [s.n.] (2010). 
[33] ICG. Validation of Analytical Procedures: Text and Metodology Q2 (R1). 4. ed. [S.1.]: [s.n.], (2005).

[34] IUPAC. Harmonized guidelines for single laboratory validation os methods of analysis. [S.1.]: [s.n.], (2002).

[35] ANVISA. Resolução RE no 899, May 29. [S.1.]: [s.n.], (2003).

[36] Validation of Analytical Precedures: Text and Methodology Q2 (R1). Current Step 4 version. ICH Harmonized Tripartite Guideline, (2005).

[37] Harmonized guidelines for single laboratory validation on methods of analysis. International Union of Pure an Applied Chemistry (IUPAC), (2002).

[38] Eurachem/CITAC Guide - Quantifying Uncertainty an Analytical Measurement, Second Edition, CITAC, LGC, UK, (2000).

[39] [The Guide to the Expression of Uncertainty in Measurement (ISO GUM), 3a Brazilian edition, INMETRO, Rio de Janeiro, RJ, (2003).

[40] Guia Eurachem/Relacre 2. Exemplos de Cálculos de Incertezas. Relacre, Lisboa, Portugal, (2012).

[41] P. C. Meier; R. E. Zund. Statistical Methods in Analytical Chemistry. 2. ed. New York: John Wiley \&Sons, V. 153, (2000). 115-118.

[42] ABNT. Requisitos gerais para a competência de laboratórios de ensaio e calibração. In: NBR, A. ISO/IEC 17025: 2005. [S.1.]: [s.n.].

[43] S. V. C. Souza; R. G. Junqueira. A procedure to assess linearity by ordinary least squares method. Analytica Chimica Acta (2005), v. 552, p. 25-35, ISSN 1-2. doi.org/10.1016/j.aca.2005.07.043

\section{Appendix A}

LOD and LOQ graphic calculations (see Method Validation). This calculation is based on crossing between prevision / analytical curves. Figure A.1 shows the pertinent curves. For LOD, the superior prevision limit (SPL) curve intercept is interpolated on analytical curve. For LOQ, the same point is interpolated on inferior prevision limit (IPL) curve.

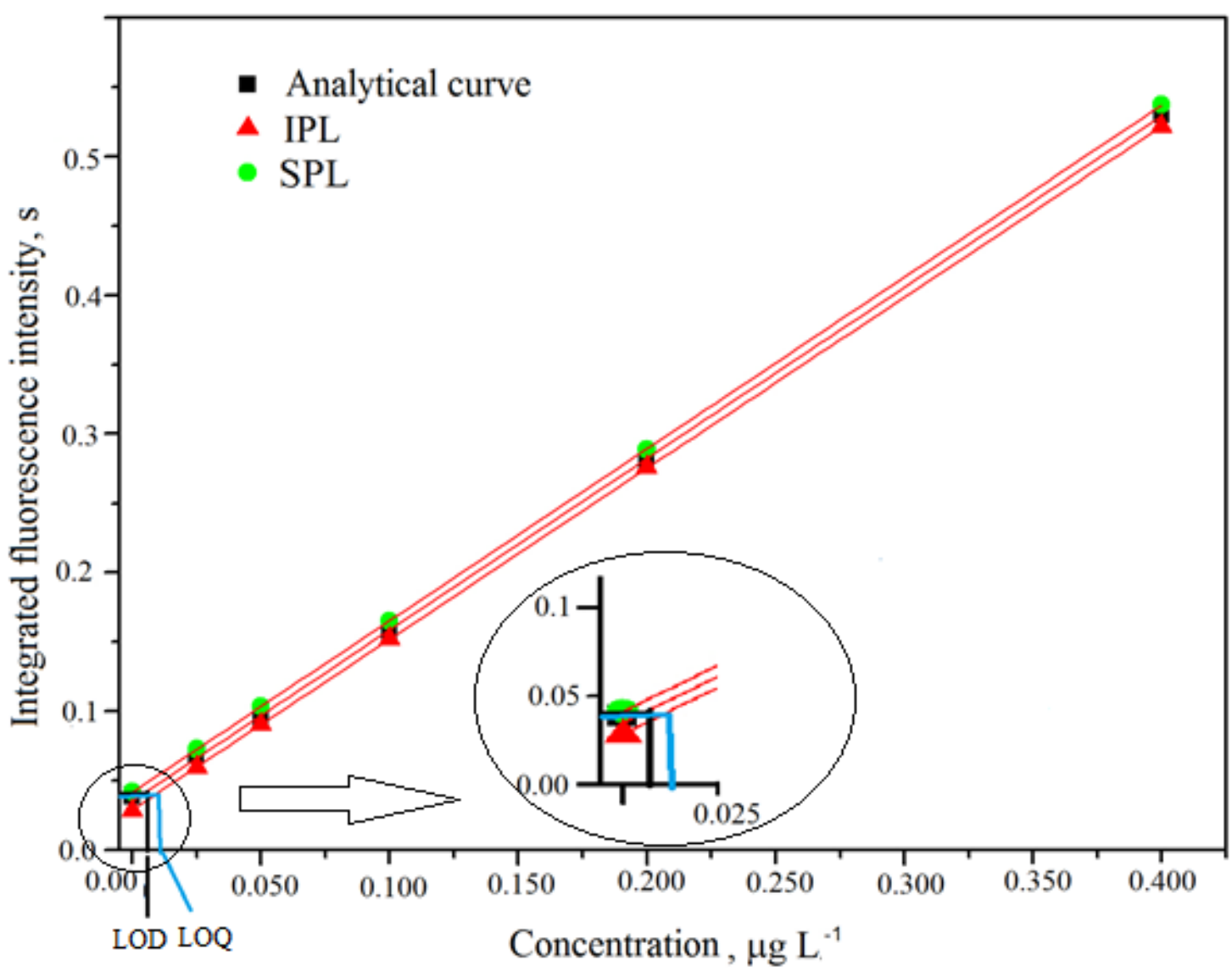

Fig. A.1. Crossing between prevision / analytical curves. 
Method Validation of Total Mercury in Petroleum Green Coke Samples By Cold Vapor Atomic Fluorescence Spectrometry (CVAFS): A Metrological Approach

\section{Appendix B}

Sensitivity Coefficients calculation for final uncertainty. Based on measurement equation (see section 3.4).

$$
\begin{aligned}
& \text { For } w \text { : } \\
& \frac{\partial C}{\partial w}=\frac{V_{F 2}}{V_{\text {pip }}} \times \frac{V_{F 1}}{m_{\text {am }}}=\frac{15 \mathrm{~mL}}{0.75 \mathrm{~mL}} \times \frac{0.05 \mathrm{~L}}{0.1 \mathrm{~g}}=10 \mathrm{Lg}^{-1} \\
& \text { For } V_{F 2} \text { : } \\
& \frac{\partial C}{\partial V_{F 2}}=\frac{w}{V_{\text {pip }}} \times \frac{V_{F 1}}{m_{\text {am }}}=\frac{13.8 n g L^{-1}}{0.75 \mathrm{~mL}} \times \frac{0.05 \mathrm{~L}}{0.1 \mathrm{~g}}=9.2125 \mathrm{ngg}^{-1} \mathrm{~mL}^{-1} \\
& \text { For } V_{F 1} \text { : } \\
& \frac{\partial C}{\partial V_{F 1}}=\frac{w}{V_{\text {pip }}} \times \frac{V_{F 2}}{m_{a m}}=\frac{13.8 n g L^{-1}}{0.75 \mathrm{~mL}} \times \frac{15 \mathrm{~mL}}{0.1 \mathrm{~g}}=2763.7 \mathrm{ngg}^{-1} \mathrm{~L}^{-1} \\
& \frac{\partial C}{\partial V_{\text {pip }}}=\frac{w \times V_{F 1} \times V_{F 2}}{m_{\text {am }}} \times\left(-\frac{1}{V_{\text {pip }}^{2}}\right)=-\frac{13.8 n g L^{-1}}{(0.75 \mathrm{~mL})^{2}} \times \frac{15 \mathrm{~mL}}{0.1 \mathrm{~g}} \times 0.05 \mathrm{~L} \\
& =184.2 \mathrm{ngg}^{-1} \mathrm{~mL}^{-1} \\
& \text { For } m_{a m} \text { : }
\end{aligned}
$$

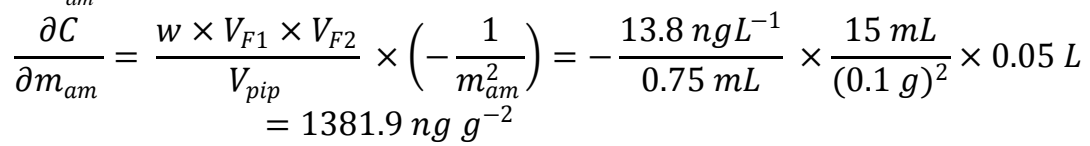

\section{AUTHORS' BIOGRAPHY}

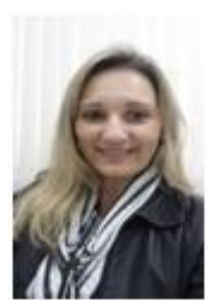

Adriana Simane Camera, She has a degree in Chemistry at the University Unilasalle (2005) and a PhD in Analytical Chemistry from the Federal University of Santa Catarina (2015). She is currently professor from Federal Technological University of Paraná, Brazil (since 2017). Mass spectrometry, X-ray spectroscopy, atomic fluorescence spectrometry, atomic and molecular spectroscopy are among her most studied analytical techniques.

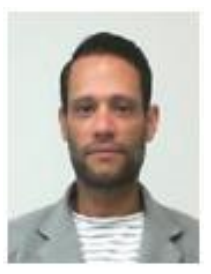

Fernando J. S. Oliveira, Chemical engineer, Dr Fernando J S Oliveira (D.Sc.) develops current research on industrial waste minimization, waste recycling/reusing, treatment alternatives for hazardous wastes and new developments in the analysis of complex environmental matrices.

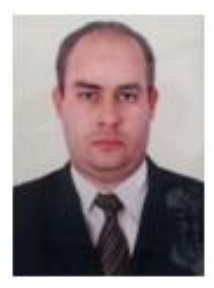

Waldemar De O. P. Filho, He has a degree in Chemistry at the Institute of Chemistry at the University of Brasilia (2003) and a PhD in Analytical Chemistry from the Institute of Chemistry of São Carlos, University of Sao Paulo (2013). He is currently Regulation Specialist from National Agency of Petroleum (ANP, Brazil), which is the agency from Brazilian government to regulate the petroleum, fuels and biofuels market. He has evaluated the suitability of the international test methods to certificate biodiesel for Brazilian scene since 2006. At the same time he has applied good laboratory pratices and metrological tools to optimize new test methods for biodiesel certification. Gas chromatography, mass spectrometry, atomic and molecular spectroscopy are among his most studied analytical techniques in this context.

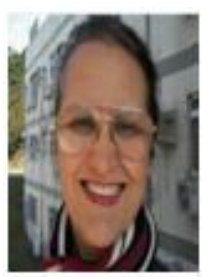

Vera L. A. Frescura, She is a full professor of chemistry at Universidade Federal de Santa Catarina (UFSC), Santa Catarina state, Brazil. She obtained her $\mathrm{PhD}$ in chemistry at Universidade Federal de Santa Catarina (1995). Her research topics are related to development of analytical methods for subsequent metals and non-metals trace determination in environmental samples through spectrometric techniques. 